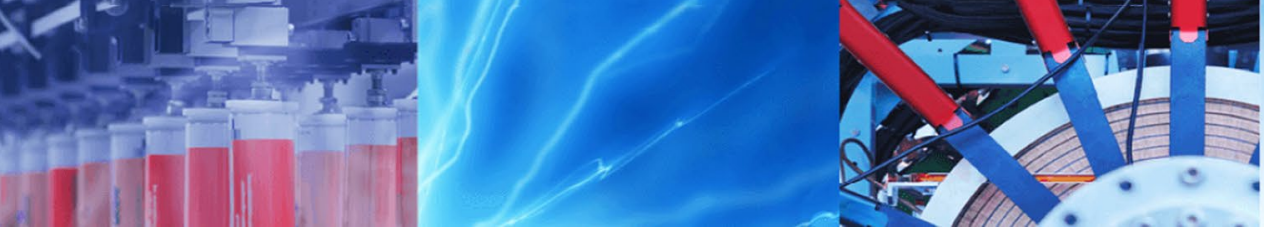

Research Article

\title{
Development of in-situ adaptive controller for end milling based on vibration feedback
}

\author{
L. Vamsi Krishna Reddy ${ }^{1}$ Balla Srinivasa Prasad ${ }^{2} \cdot$ N. Harsha Raghuram ${ }^{3} \cdot$ M. Rajasekhar ${ }^{2}$
}

Received: 3 July 2020 / Accepted: 29 December 2020 / Published online: 23 January 2021

(c) The Author(s) 2021 OPEN

\begin{abstract}
This study establishes a tool condition monitoring methodology builds on the vibration signal attained via data acquisition system which is integrated with the in house developed adaptive controller for an end milling. As the quality of the products and the machine tool performance are the key parameters in maintaining machine stability. Proposed Adaptive control optimization system is validated with the experimentation trials and data analysis on 3 axis CNC milling machine. The rotational speed of the spindle and vibration signals is found to be reactive to milling cutter condition and therefore capable of sustaining the set-out methodology. A novel hybrid transformation, coupled with FFT and HHT is proposed to distinguish between a source of variation for adaptive control optimization, cutting region with the non-cutting region. In this study, decisions are made to evaluate the tool condition by combining all related information into a rule base. The investigation trajectories unveil the established system be able to accomplish the mechanism properly as anticipated.
\end{abstract}

Keywords Adaptive controller · End milling · Vibrations · Hilbert huang transform (HHT) · Fast fourier transform (FFT) . Hybrid transformation

\section{Introduction}

Usually, throughout the machining process, 3 diverse vibrations can arise owing to the absence of rigidity of solitary or numerous essentials of the system composed by the tool holder, machine tool, workpiece and cutting tool material. These vibrations are well known as free vibrations, forced vibrations and self-excited vibrations. Free vibrations take place as soon as the mechanical system is displaced from its equilibrium and is permitted to vibrate without restraint. Forced vibrations emerge owing to outside excitations. Every tooth on the milling cutter enters and exits the workpiece is identified as the primary cause of forced vibrations in the milling process. However, both free and forced vibrations can be avoided or reduced once the source of the vibration is identified [1].
Nevertheless, regenerative chatter i.e., self-excited vibrations take out energy from the interaction between the workpiece and cutting tool throughout the machining operation. This trend is a consequence of an uneven interaction stuck between the structural deflections and machining forces as well [2]. The cutting forces generated as soon as the cutting tool and workpiece come into contact generate noteworthy structural deflections [3]. These structural deflections vary the chip thickness that, in turn, unorthodoxies the cutting forces [4]. Regenerative chatter can result in extreme cutting forces, tool wear, tool letdown, and scrap part due to objectionable surface roughness, therefore severely decrease productivity in operation and part quality [5]. Vibrations emerge under the excitation applied via material deformation throughout the machining of a workpiece. These regenerative vibrations (chatter) will influence the outcome of machining

Balla Srinivasa Prasad, bsp.prasad@gmail.com | ${ }^{1}$ Department of Mechanical Engineering, SRIT, Anantapur, India. ${ }^{2}$ Mechanical Engineering, GIT, GITAM Deemed to be University, Visakhapatnam, India. ${ }^{3}$ Maruthi Suzuki India Limited, New Delhi, India. 
operation, in specific, the surface finish and tool life can be decreased. In a machining operation, chatter is an unsteady active occurrence which causes overcut and rapid tool wear, etc. [6]. In regular CNC milling operation, cutting parameters are generally selected agreeing to toolmaker's handbooks, and the cutting parameters carefully chosen are typically conservative to evade machining letdown. Even though cutting parameters are optimized offline by an optimization procedure, they cannot be attuned throughout the cutting operation, as the cutting process is adjustable due to vibrations, tool wear, temperature, and any other disturbances [7]. To safeguard the quality of machined parts, and to decrease the machining expenses and increase the machining productivity, it is required to optimize and regulate the machining operation in real-time. Consequently, cutting parameters need to be attuned in situ condition to fulfill optimal machining measures [8].

Fundamentally, the well-timed finding of cutting tool associated problems that would typically be part of the obligation of the machinist presents a perceptible challenge. For this purpose, excessive research work has been commenced into effective tool condition monitoring systems [9]. Till date, it is proper to relate that the problems of data acquisition, signal analysis, and decision making together with system installation and operating expenses means that, very few such methodologies have established their way into marketable applications [10]. Tong et al. [11] developed an intelligent manufacturing method by adopting a multisensor fusion technology for real-time data acquisition and processing.

In general, CNC processes are ratified with the direct control of a computer frequently deprived of being uninterruptedly controlled by an operator. A review of the AC system is presented in [12]. Three types of ANC's namely identified [13], first one is Adaptive control with constraint (ACC), the second one is Geometry adaptive control (GAC) and the third one is Adaptive control with optimization (ACO). The adaptive controller industrialized in the present study fit into the third classification in which the cutting parameters are calculated and controlled in imperative to optimize a definite index of cutting performance, such as decrease of vibration, amassed of efficiency, enhancement of surface finish, and control of the tool flank wear. Adaptive controllers (AC) are devices that adjust cutting parameters to accomplish a certain level of performance. In the case of milling operation, the control panels on which $A C$ acts are the rotational speed of the spindle and the feed rate. Adaptive controllers (AC) are the devices that regulate the process parameters to achieve a certain performance. In the present work, an adaptive control optimization (ACO) system is planned to optimize milling process parameters based on vibration parameter values.
Consequently, tool wear and vibrations parameter outcome can be predicted. In the proposed AC system, feed rate and spindle speed are attuned in real-time in order to sustain vibration parameters values under threshold irrespective of variants in milling conditions. The determination is to propose an innovative methodology to enrich the adaptive controller by comprising a consistent adaptive model relating to machining conditions. Present adaptive controller permits steady cuts free from both forced and self-excited vibrations, at reduced tool deflection and tool wear, while maintaining efficiency and sustaining the constraints associated with spindle power and cutting forces.

Firstly, the introduction was presented with appropriate references. Then the proposed adaptive controller configuration was made followed by the validation and experimentation. The next step is the development of Strategy for an In-House Adaptive Controller. Finally, results were presented and discussed in detail.

\section{Configuration of the proposed adaptive controller}

To develop the adaptive controller, it requires interfacing between the vibration sensor and SC06 CNC machine controller driver. An in house adaptive controller is developed which is used to govern the NC machine controller (SC06) based on the vibration feedback received from the Kistler accelerometer. The configuration of the proposed design of the adaptive controller is presented in Fig. 1. The validation of the proposed controller for CNC end milling operation is carried out in-situ condition. Outcome of all the mentioned steps is an expected consequence of adaptive controller implementation. All the stages explained with full details in Sect. 4.1.

The details of this adaptive controller will be enlightened in the next section. The part programmer develops an offline optimized set of speed, feed and depth of cut parameters for a particular machining operation (in this study, milling) and feeds the program into the GUI Interface. This interface networks with machining controller, translates the CNC commands into servo drive commands sequentially, and is executed chronologically.

\section{Experiment design and equipment details}

The investigational test set up in Fig. 2, comprising of a 3 axis CNC Milling machine possesses high-speed spindle, $3.5 \mathrm{KW}$ spindle, rated at 18,000 RPM. Kistler 8793 accelerometer mounted on a spindle housing to enable vibration 


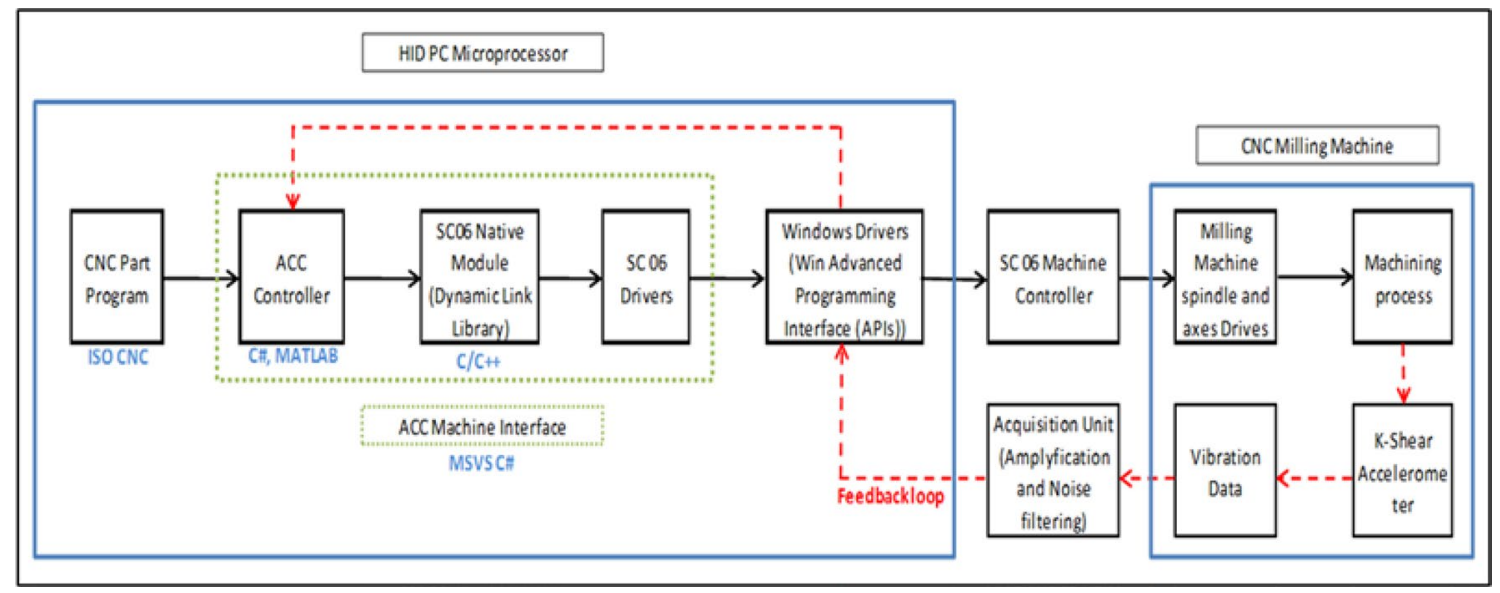

Fig. 1 Configuration of the proposed adaptive controller

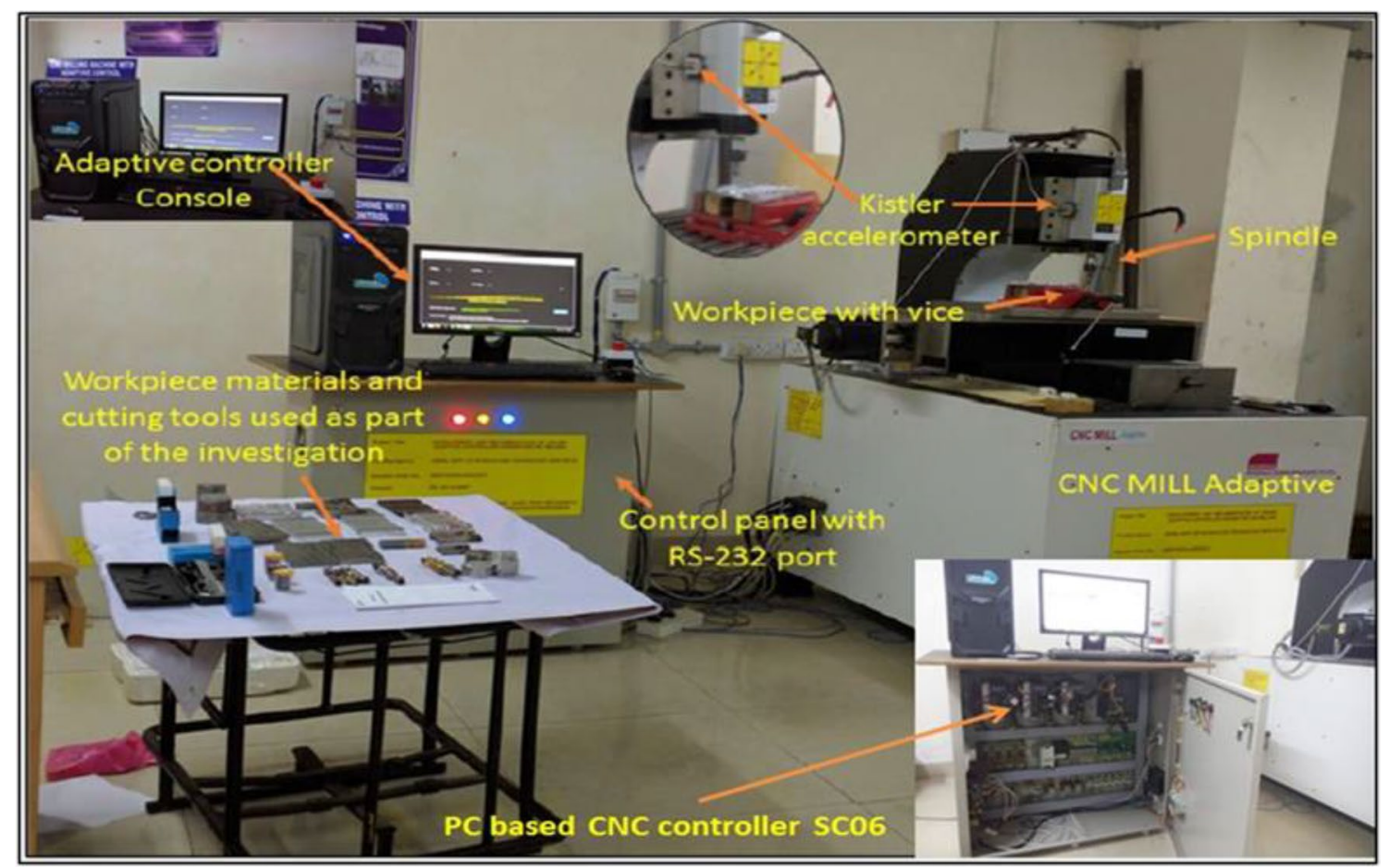

Fig. 2 Experimental setup

monitoring and a PC-based CNC controller SC06 to interface with the accelerometer.

As part of the present investigation, Al7075 specimen used as workpiece materials in form of plate with dimensions of $150 \mathrm{~mm} \times 100 \mathrm{~mm} \times 15 \mathrm{~mm}$ and a solid carbide end mill cutters possess $\varnothing 12 \mathrm{~mm}$ is used as cutting tool. For experimental trails, three cutting parameters in three levels are considered. Hence, according to the Taguchi method L9 orthogonal array is employed for the investigation.
Table 1 offers the cutting parameter levels and factors used for the investigation. Table 2 provides the mechanical properties of work piece material Al7075 alloy. Solid carbide end cutters of $\varnothing 12 \mathrm{~mm}$ diameter are used as a cutting tool material. The cutting tools for the cutting tests are DIN 338 standard mill cutter of $\varnothing 12 \mathrm{~mm}$ is selected. Throughout the experimentation, dry machining condition is maintained. Cutting forces are continuously measured with Kistler force dynamometer at machining combinations by keeping the constant depth of the hole as $8 \mathrm{~mm}$. 
Table 1 Factors and levels used in the experimentation

\begin{tabular}{llll}
\hline Factors & \multicolumn{2}{l}{ Levels } \\
\cline { 2 - 4 } & 1 & 2 & 3 \\
\hline Spindle speed, N (RPM) & 5700 & 7125 & 8545 \\
Feed rate, f (mm/min) & 160 & 100 & 80 \\
Depth of cut(mm) & 1.0 & 1.5 & 2.0 \\
Workpiece hardness, BHN & 150 & & \\
Cutting tool material & Solid carbide (uncoated) & \\
\hline
\end{tabular}

Table 2 Mechanical properties and chemical composition of workpiece material Al7075 alloy

\begin{tabular}{ll}
\hline Material properties & $\mathrm{Al}-7075$ \\
\hline Density $\left(\mathrm{kg} / \mathrm{m}^{3}\right)$ & 2800 \\
Young's Modulus (GPa) & 72 \\
Hardness $(\mathrm{HV})$ & 175 \\
Yield Strength $(\mathrm{MPa})$ & 503 \\
Tensile Strength $(\mathrm{MPa})$ & 572 \\
Thermal Conductivity $(\mathrm{W} / \mathrm{m}-\mathrm{K})$ & 130 \\
Thermal expansion coefficient $(\mathrm{CTE})\left(10^{-6} /{ }^{\circ} \mathrm{C}\right)$ at $0-100^{\circ} \mathrm{C}$ & 23.2 \\
\hline
\end{tabular}

Work pieces are made to introduce certain wellspring of variation in cutting conditions like gaps (in this particular study). So cut plan is also designed in such a way that cutter comes in contact with workpiece for some time and does not cut some does not interact with the work piece in gaps.

\section{Development of strategy for an in-house adaptive controller}

In house developed adaptive controller package by using MATLAB, which runs on standard G/M codes-this has been exported using GUIDE and MCR to enable adaptive control algorithm to run in real-time as per adaptive control logic. The strategy adopted in the proposed adaptive controller is shown in Fig. 3. To collect the vibration data, a Kistler 8793 accelerometer is mounted on the spindle head as shown in Fig. 2. This model of accelerometer has an optimum sensitivity of almost $10 \mathrm{mv} / \mathrm{G}$ in altogether with three axes. Vibration data is conditioned through a vibration filter and then received to $P C$ through a special driver.

The part program is prepared with optimized machining parameters and cutting is initiated. Initially, there is no feedback data available from vibration devices. Therefore, the ACC controller relays the CNC program command to SC06 driver. This driver, in turn, activates the SC06 controller to execute the machining command. Vibration data is collected from K-shear accelerometer, with the help of windows driver advanced programming interfaces (APIs). Once machining starts the ACC controller uses PC microprocessor to compute the corrected machining parameters (speed, feed and doc) according to vibration parameter values acquired in the form of feedback. The aforementioned ACC controller is programmed in C, C\#, $\mathrm{C}++$ and MATLAB. This controller gets raw vibration signal from conditioning devices, calibrates it to values of

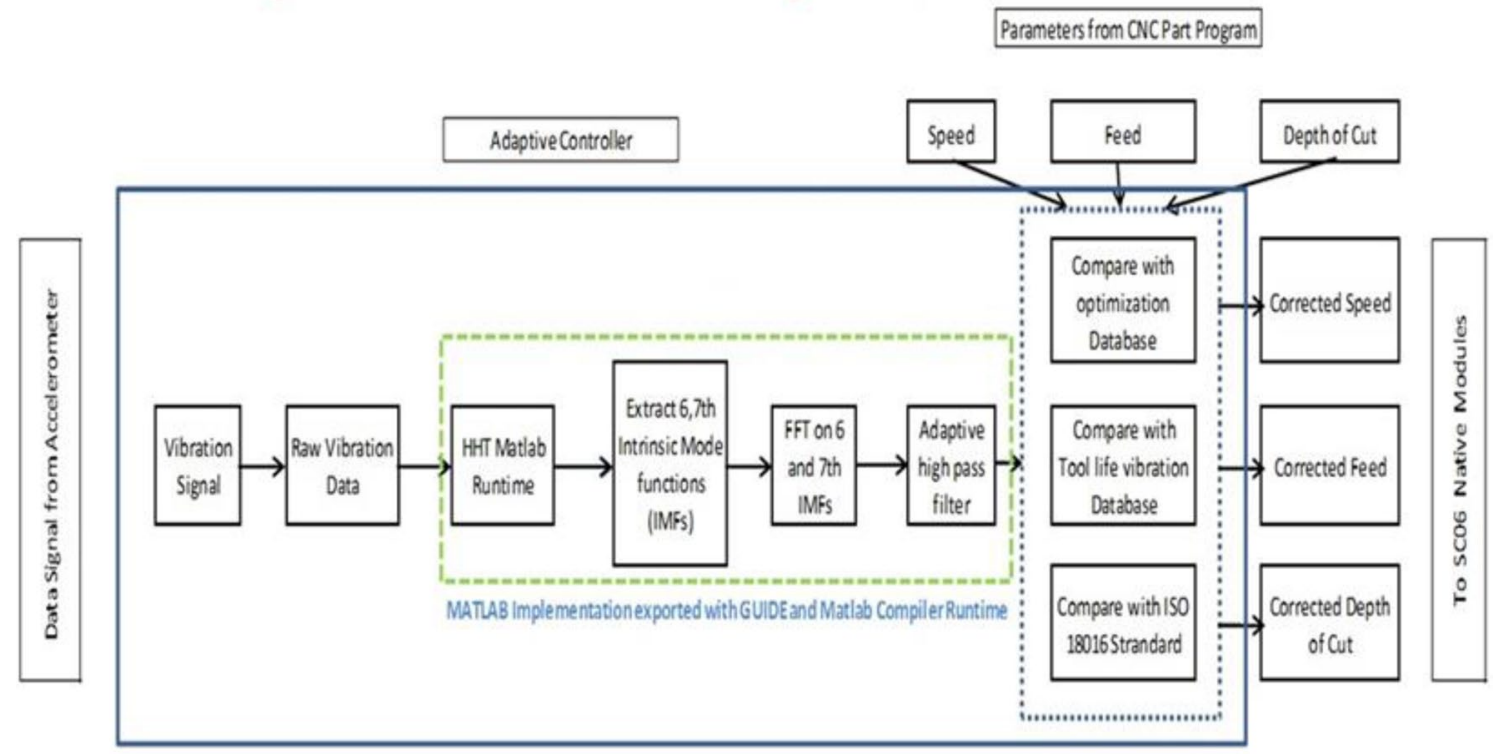

Fig. 3 Adaptive controller strategy implemented on CNC machine 
acceleration unit based on Kistler data specification sheet. At present, the actual vibration data is fed into the proposed hybrid transformation, which is a combination of HHT and FFT [14]. The output from this stage is used in the decision of whether the individual machining parameters can be increased or decreased. Some threshold limits are also applied to decision-based on the result in accordance with ISO 10,186-3 standard [15]. Cheddadi et al. [16] demonstrated the design of an intelligent loT enabled energy monitoring system and effectively implemented at photovoltaic stations.

\subsection{In-situ implementation of an adaptive controller}

This section presents the various stages in the design and implementation of the adaptive controller based on vibration feedback. Major stages of the controller design and implementation are pictorially represented in Fig. 4.

Figure 4a gives input phase of adaptive controller for specific machining application. In addition to milling, this controller logic can be applicable to drilling, turning and boring as well. But the results of this manuscript is limited to milling operation only. Figure $4 \mathrm{~b}$ presents the data acquisition phase whereas as Fig. $4 \mathrm{c}$ represents the signal conditioning followed by actual implementation of adaptive controller strategy for milling. The part program is offline optimized by the part programmer, further relayed to ACC Controller on PC. The design of adaptive controller comprises of nine major stages as shown in Fig. 4. The first stage gives the option to make the selection regarding machining operation. Optimized machining parameters are fed to the SC06 controller in the second stage and required part program is generated to initiate the cutting process. Details of the process condition are entered into the controller in the third stage. The fourth stage gives the scope for selecting the required milling cutter from the tool's database associated with the adaptive controller whereas the fifth stage allows us to choose the desired cutting plan. Stage 6 is the process data stage, where all the boundary conditions must be furnished. Stage 7 is a data acquisition module where the user is allowed to customize sample size data set, number of samples and average count etc.

In stage 8, signal analysis is carried out for acquired vibration data. This stage consists of threshold parameters (machine and vibration safety) in FFT and hybrid Transformation or coupled FFT and HHT is represented as RRT. Final stage 9 gives the implementation phase of in house developed adaptive controller along with the part program in real-time.

\subsection{Cut planning}

The actual cutting tool interactions with the work piece during the materials and slots are illustrated in Fig. 5. Initially for analysis, a separate phase of the controller is also designed which takes inputs from CNC program, cut plan and present cutting parameters (rotational speed of the spindle, feed rate and depth of cut) to group vibration samples into cutting and non-cutting vibration data.

\subsection{Modeling of proposed hybrid transformation (RRT)}

According to the proposed Hybrid Transformation or coupled FFT and $\mathrm{HHT}$, the acquired intrinsic mode functions (IMFs) from empirical mode decomposition (EMD) are converted into frequency spectrum by using Fast Fourier transformation (FFT).

For a vibration signal $x(t)$ in the time domain, its frequency spectrum is defined as,

$x(t)=\sum_{k=0}^{\infty} C_{k} \cdot e^{j 2 \pi k F_{0} t}$

where, $F_{0}=\frac{1}{T}$ is the fundamental frequency.

$C_{k}$ is the kth Fourier series coefficient or kth harmonic coefficient.

$\mathrm{e}^{\mathrm{j} 2 \pi k F_{0} t}=\cos \left(2 \pi k F_{0} t\right)+j \sin \left(2 \pi k F_{0} t\right)$, is a complex sinusoid.

And,

$C_{\mathrm{k}}=\frac{1}{T}\left[\int_{-\infty}^{\infty} x(t) \cdot e^{-j 2 \pi k F_{0} t} \mathrm{dt}\right]$

Substituting Eq. 2 in Eq. 1, the complete frequency spectrum of $x(t)$ can be represented as:

$X(F)=\frac{1}{T} \sum_{-\infty}^{\infty}\left[\int_{-\infty}^{\infty} x(t) e^{-j 2 \pi k F_{0} t} \mathrm{dt}\right] \cdot e^{j 2 \pi k F_{0} t}$

This Eq. (3) has been numerically computed using MAT$L A B$ for a discretized vibration signal and spectrum of cutting and non-cutting regions are shown in Fig. 6 (Cutting) and Fig. 6 (Non-Cutting). Also, instead of converting the whole vibration signal directly into the frequency spectrum, Empirical mode decomposition (EMD) of the time domain signal is done as described in [17], to obtain Intrinsic Mode Functions (IMFs). An IMF is defined by below two characteristics: 


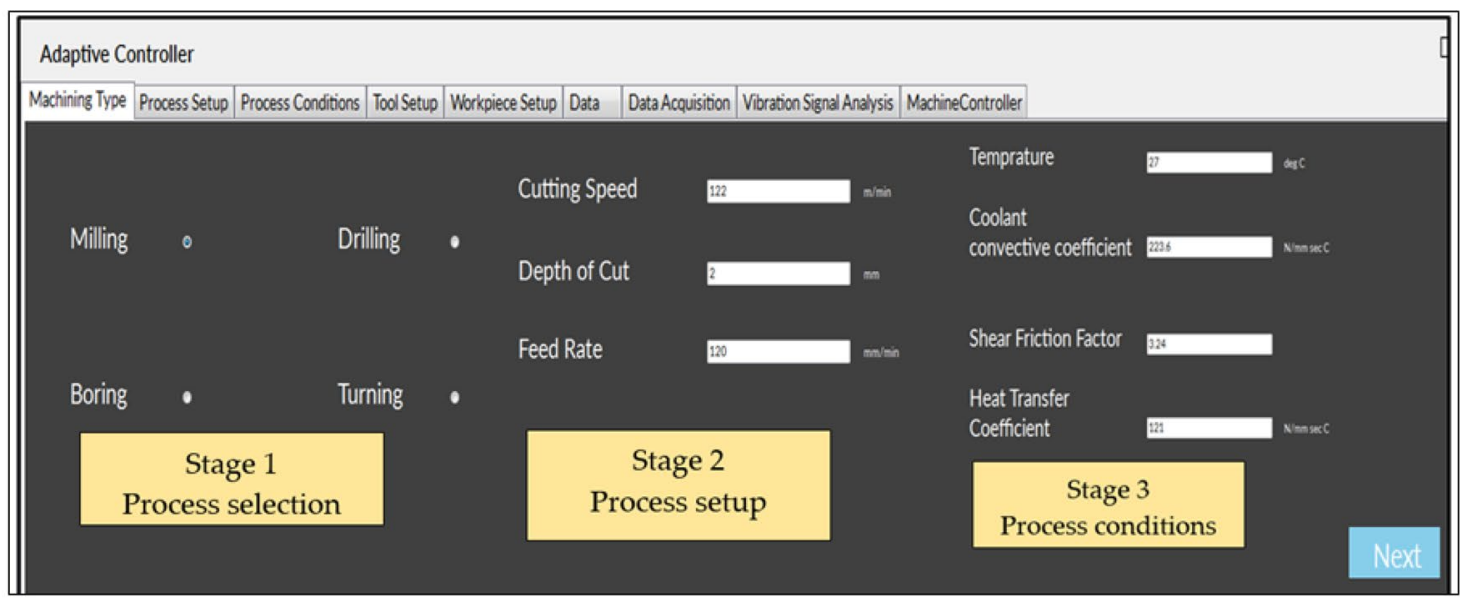

a Phase 1 adaptive controller process setup

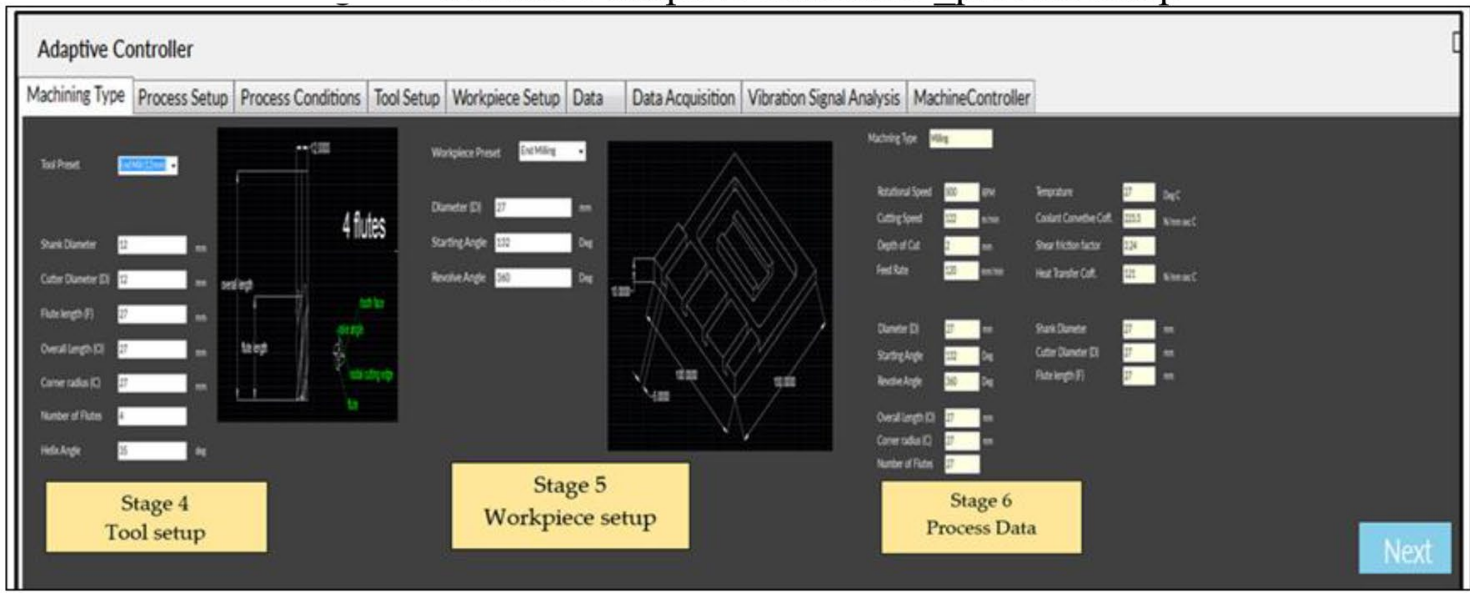

b Phase 2 adaptive controller_data acquisition

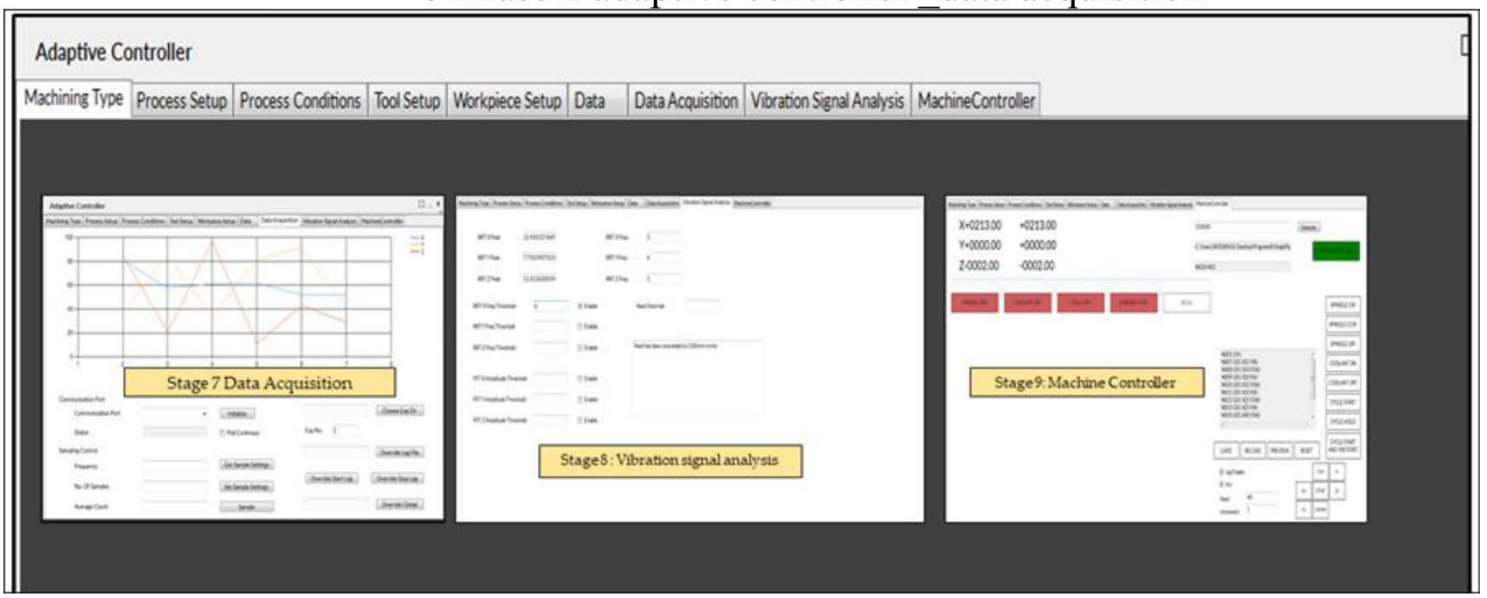

c Phase 3 adaptive controller_implementation

Fig. 4 a Phase 1 adaptive controller_process setup b Phase 2 adaptive controller_data acquisition c Phase 3 adaptive controller_implementation 


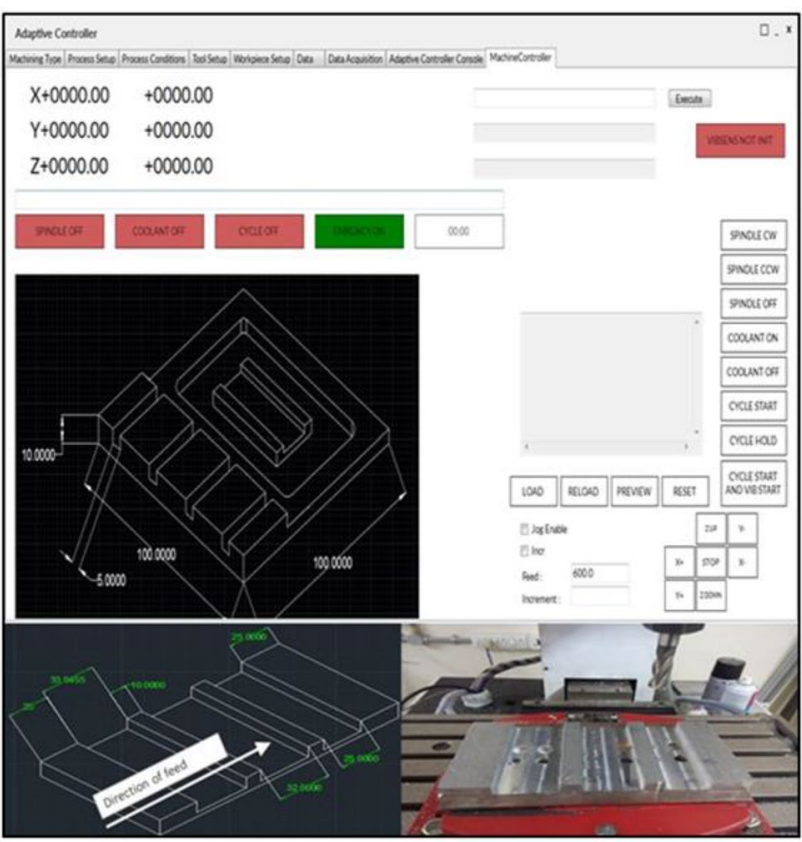

Fig. 5 Cutting plan under the in-house adaptive controller (a) Is an oscillatory function where the number of extreme and the number of zero-crossing must be either equal or differ by at most one, and,

(b) At any point, the mean value of envelope defined by local maxima and that of envelope defined by local minima is zero.

The point of all local extreme of the vibration signal is identified, two cubic splines are generated, one for local maxima and one for local minima. The mean of these two splines is given by $\mathrm{m}_{1}$. For the first proto-IMF $\mathrm{h}_{1}$, the mean $m_{1}$ is subtracted from $x(t)$,

$\mathrm{h}_{1}(\mathrm{t})=\mathrm{x}(\mathrm{t})-\mathrm{m}_{1}$

The obtained $h_{1}$ is tested, if it is an IMF based on conditions (a) and (b), Else, it's mean $\mathrm{m}_{11}$ and corresponding $\mathrm{h}_{11}$ is generated.

$\mathrm{h}_{11}(\mathrm{t})=\mathrm{h}_{1}(\mathrm{t})-\mathrm{m}_{11}$

$h_{1 n}(t)=h_{n-1}(t)-m_{1 n}$

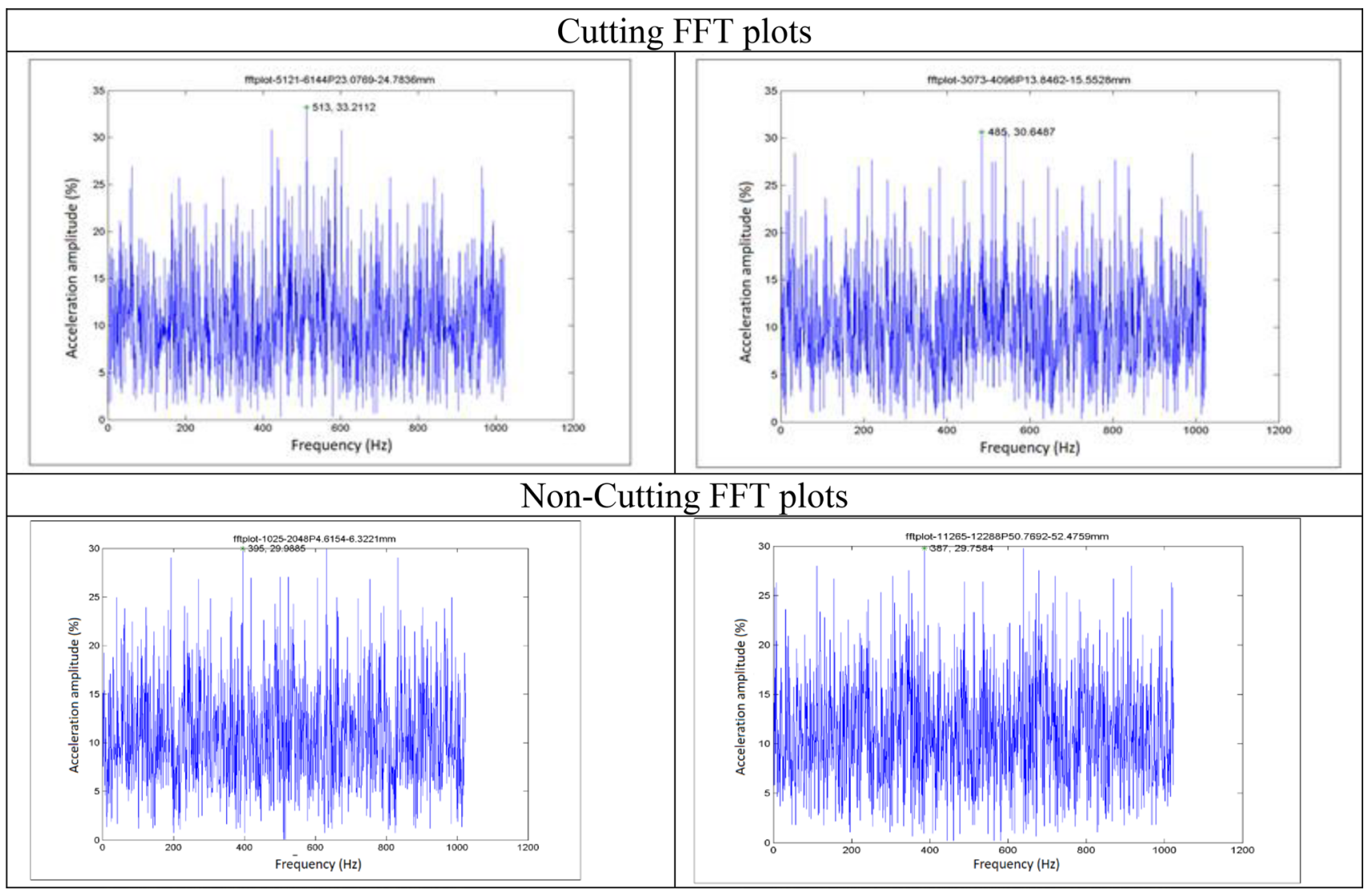

Fig. 6 Vibration signal analysis with FFT 
This process is followed until a satisfactory $h_{1 n}(t)$ is found to give $I_{1}(t)$, the first IMF.

$\mathrm{I}_{1}(\mathrm{t})=\mathrm{h}_{1 \mathrm{n}}(\mathrm{t})$

This process is continued until all IMFs are obtained from the vibration signal. Now instantaneous frequencies of the above IMFs are obtained through Hilbert transform:

$H\left(I_{n}(t)\right)=\frac{1}{\pi} P V \int_{-\infty}^{\infty} \frac{I_{n}(\tau)}{t-(\tau)} d \tau \frac{\delta y}{\delta x}$

The obtained analytical signal can be defined as follow:

$a_{l_{n}}=x(t)+j y(t)=r(t) e^{j \theta(t)}$

where, $I_{n}(t)$ represents $n^{\text {th }}$ IMF.

$r(t)=\sqrt{x^{2}+y^{2}}$

and

$\theta(t)=\tan ^{-1} \frac{y}{x}$

Instantaneous frequency can be directly obtained by

$f_{i}=\frac{d \theta}{d t}$

Equations (5-9) are numerically computed using MAT$L A B$. The sample results are presented in Figs.6-8 with proper discussion. Still, characteristic differences are not observed. As already discussed, present study uses Hybrid Transformation or coupled FFT and HHT is represented as RRT, in which the obtained IMFs from Eqs. (4) and (5) is transformed into the frequency domain using Fourier series, as,

$X_{I_{n}}(F)=\frac{1}{T} \sum_{-\infty}^{\infty}\left[\int_{-\infty}^{\infty} I_{n}(t) e^{-j 2 \pi k F_{0} t} \mathrm{dt}\right] \cdot e^{j 2 \pi k F_{0} t}$

where $I_{n}(t)$ represents $n^{\text {th }} I M F$.

Then $X_{I_{n}}(F)$ spectrum is subjected to a filter $R(F)$, which is as defined as follow,

$R(F)=\left\{\begin{array}{l}F \forall F>f_{n} \\ 0 \forall F \leq f_{n}\end{array}\right.$

where $f_{n}$ is a natural frequency of the CNC machining system used for the experiment.

In the present study, specific to the procured machine and signal conditioning system, $f_{n}=5 \mathrm{~Hz}$ is found to be most useful. The RRT spectrums for all IMFs, viz.,
$\mathrm{R}\left[\mathrm{X}_{\mathrm{I}_{1}}(\mathrm{~F})\right], \mathrm{R}\left[\mathrm{X}_{\mathrm{I}_{2}}(\mathrm{~F})\right], \ldots \mathrm{R}\left[\mathrm{X}_{\mathrm{I}_{n}}(\mathrm{~F})\right]$ are generated numerically and it is found that $R\left[X_{I_{6}}(F)\right]$ is the most useful spectrum [18], the results are illustrated in Fig. 9 in Sect. 5.

\section{Results and discussions}

Several experiments were conducted with a different set of workpieces and tool material combinations. The grouped data obtained from the controller is analyzed with various techniques to distinguish between cutting (without air gap) and non-cutting (air gap) time. Initially, FFT analysis is carried out to find out the maximum frequency and maximum amplitude but they found to be continuously varying and no characteristic inferences could be drawn.

Figure 6 gives the acceleration amplitude in the frequency domain. This is also the case with Hilbert spectral plots shown in Fig. 7. In Fig. 7, no inference is observed with regard to tool and work piece interaction and no frequency density with respect to time can also be found in any region irrespective of cutting.

After numerous experiments, the present study tried to use Hilbert-Huang transformation [19], for non-stationary and non-linear vibration. Figure 8 gives the empirical mode decomposition of the vibration signal i.e., IMFs for both cutting (without air gap) and no- cutting (air gap).

As shown in Fig. 8, it is identified that on empirical mode decomposition of the acquired data signal, the IMFs of the order greater than 4 [20], i.e., IMFs 5, 6, 7 showed some characteristic variation with respect to the tool vibrations when it is actually involved in cutting and during air gap. In the present study, IMF 6 is found to be the most useful component for differentiating whether the tool is actually cutting or not. In simpler terms [21], the IMF6 is found to be possessing higher harmonics in case of cutting and lower harmonics in case of air gap operation (i.e., non-cutting region) as shown in Fig. 8. But these harmonics could not be quantified with HHT.

To overcome this, a hybrid transformation is proposed which is a combination of HHT and FFT. This hybrid transformation is termed as RRT. According to the proposed transformation (RRT), the acquired intrinsic mode functions (IMFs) from empirical mode decomposition (EMD) are converted into a frequency spectrum by Fast Fourier transformation [22]. Later, obtained spectral values are passed through a threshold filter that cuts of frequencies having amplitude $<0.5 \mathrm{~mm} / \mathrm{sec} 2$ and only the frequencies of interest are analyzed and they are presented in Fig. 9. 


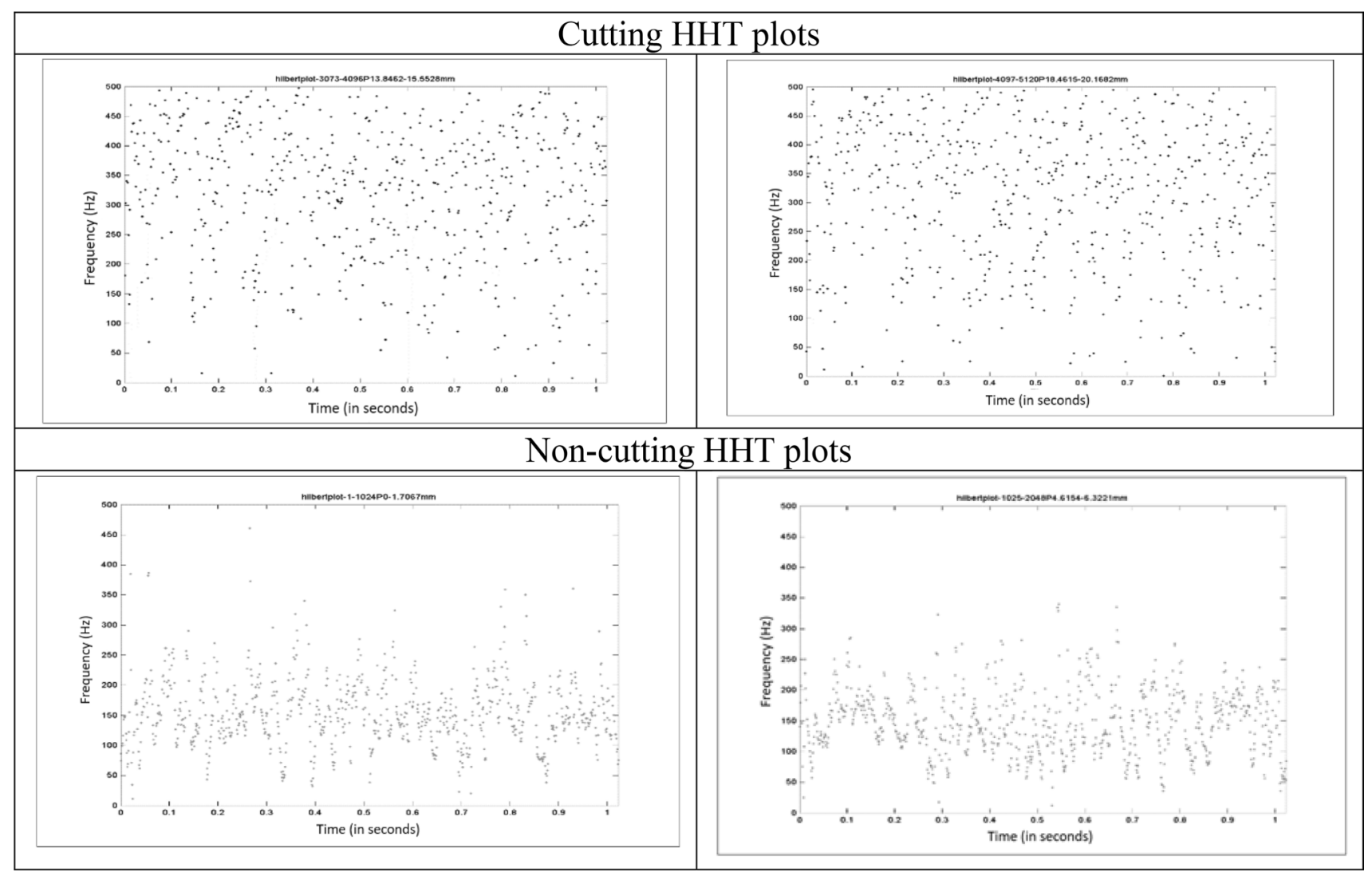

Fig. 7 Vibration signal analysis with Hilbert Transform

RRT analysis plots shown in Fig. 9 represent the 2 cases. Figure $9 \mathrm{a}$ indicates the cutting condition and Fig. $9 \mathrm{~b}$ represents the air gap condition. It is identified that when cutting process is carried out the peaks of the RRT plot are typically in the range of $1-5 \mathrm{~Hz}$ and while passing through the air gap the peaks of the plot shifted to higher frequencies i.e., 7-10 Hz. To confirm the same fact, the new 3,162 datasets RRT plots for IMF6 and IMF7 are generated. The peak values in each plot are calculated, their frequency of occurrence. Table 3 gives the RRT Peak frequencies for while cutting whereas Table 4 presents the RRT Peak frequencies for non-cutting i.e. when the air gap is present.

These results are implemented and validated on the core of the adaptive controller in Fig. 1 in real-time. Based on the RRT result, the adaptive controller identifies the cutting tool and workpiece interactions. Once identified, there are a set of feed rate/rotational speed steps that can be defined, for which the ACO will make a decision whether to step up or step down the machining parameters. If any vibration sample's RRT peak results in $9 \mathrm{~Hz}$, then adaptive controller checks if the feed rate can be optimized or not. For example, if the present table feed rate is $120 \mathrm{~mm} / \mathrm{min}$ and the predefined steps allow a feed rate up-gradation to $240 \mathrm{~mm} / \mathrm{sec}$, subsequently in-house adaptive controller overrides the part program feed rate. This enables to decrease the production time and thereby cost.

\section{Conclusions}

An in-house adaptive controller has been designed based on vibration data. To facilitate the data acquisition in realtime, integration is established between programmable PC-based CNC controller Interface SC06 with a vibration signals transducer Kistler 8793 K-Shear Tri-Axial accelerometer through MATLAB program routine to work under the designed controller. In the present study, a hybrid novel approach proposed which is a combination of HHT and 


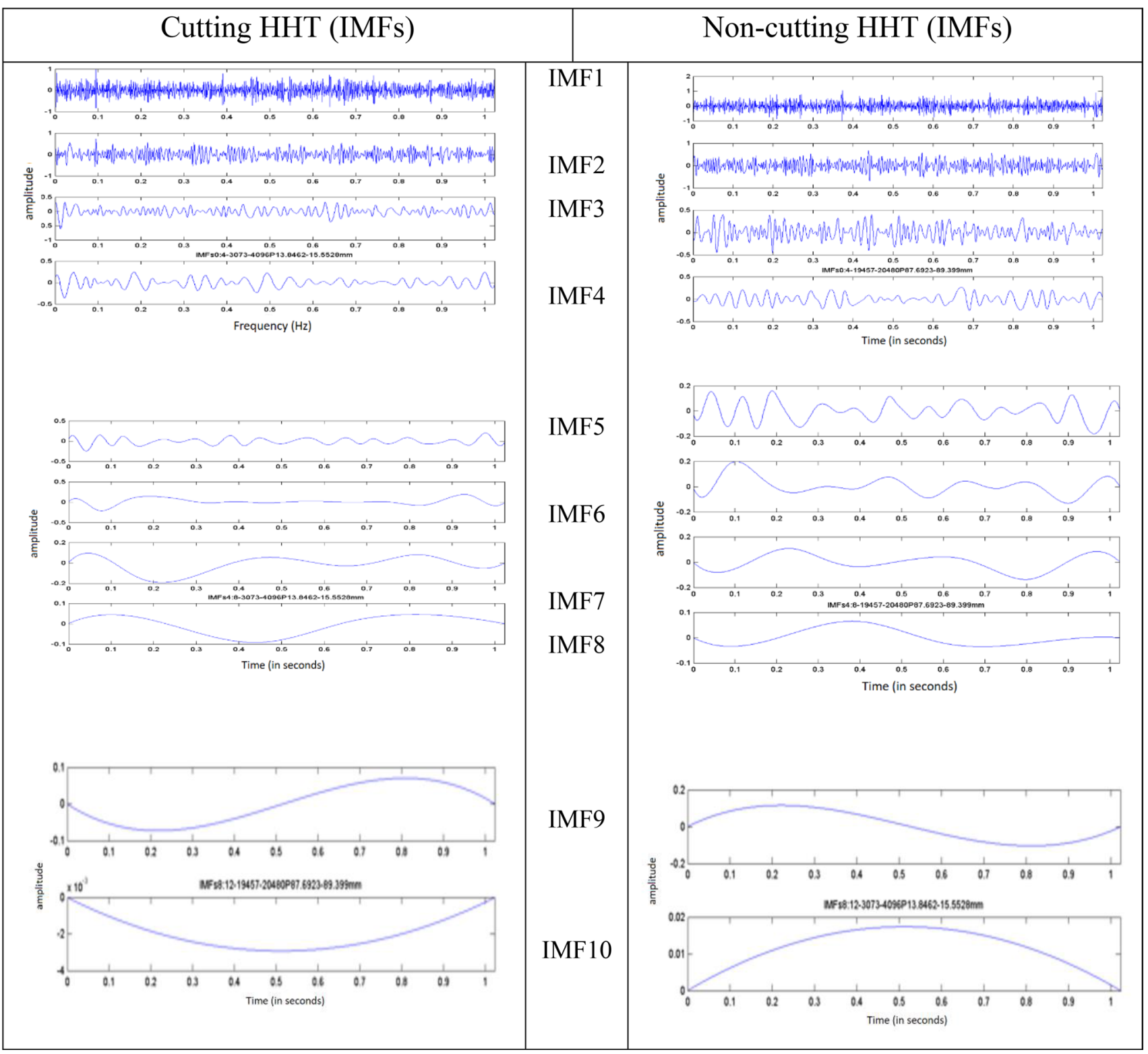

Fig. 8 Empirical mode decomposition of the vibration signal i.e., IMFs for both cutting (without air gap) and non-cutting (air gap)

FFT and implemented successfully in real-time for end milling operation. It is also found that proposed RRT transformation is more effective for identifying the variations in tool-workpiece interactions such as air gaps while cutting.

This adaptive controller controls the milling process parameters in real-time and maintains vibration under a preset safety threshold value by means of driver interfacing for adaptation of machining parameters. Applicability of the method for the adaptive alteration of milling parameters is demonstrated and tested on a 3-axis CNC milling machine with experimental trails [23]. Results of the end milling experiments with adaptive controller strategy display that the established in house controller has great sturdiness and steadiness.

The complexity of the transforms integration may be reduced with advanced software even at the acquisition of the signal as part of the future study. 


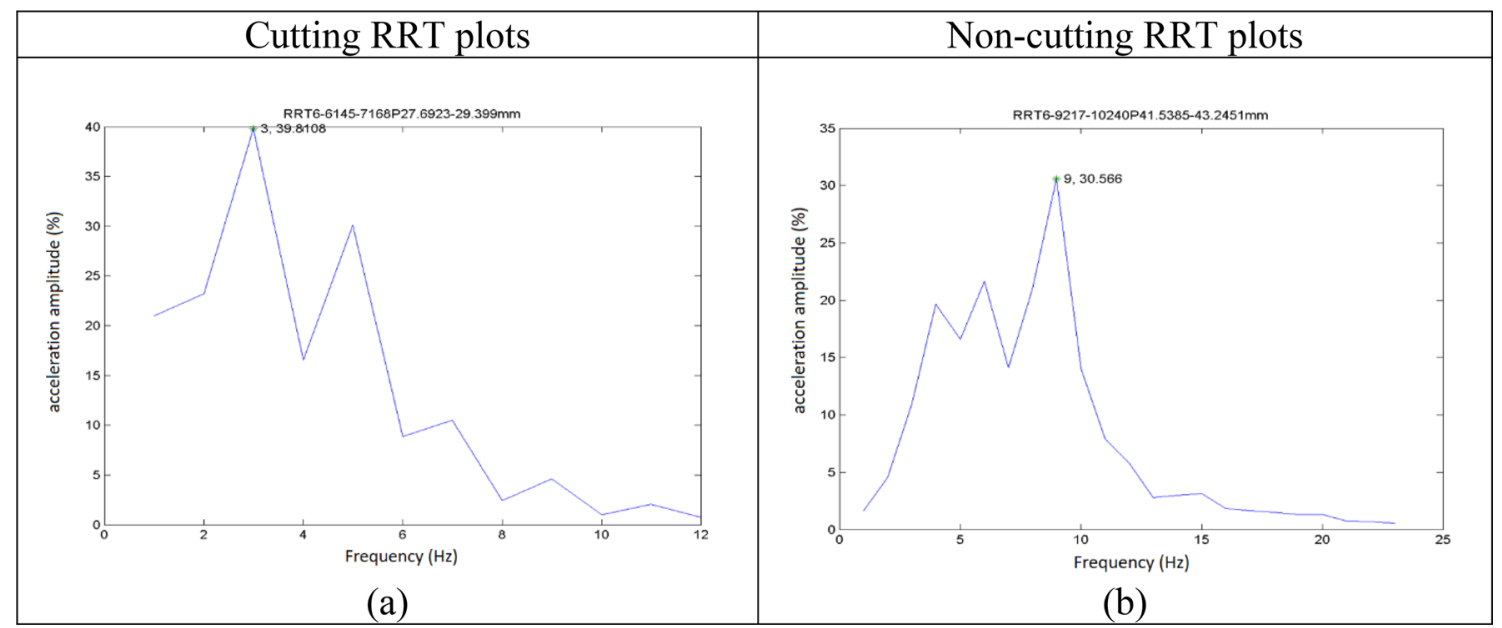

Fig. 9 Signals analysis with the proposed hybrid transformation (RRT)

Table 3 RRT Peak frequencies for cutting (without air gap)

\begin{tabular}{llclll}
\hline Sample start no & Sample stop no & $\begin{array}{l}\text { Workpiece } \\
\text { start }(\mathrm{mm})\end{array}$ & $\begin{array}{l}\text { Workpiece } \\
\text { stop }(\mathrm{mm})\end{array}$ & $\begin{array}{l}\text { Peak } \\
\text { frequency(Hz) }\end{array}$ & Peak amplitude \\
\hline 3073 & 4096 & 13.84 & 15.55 & 4 & 33.29 \\
5121 & 6144 & 23.07 & 24.78 & 5 & 18.93 \\
6145 & 7168 & 27.69 & 29.39 & 3 & 39.81 \\
7169 & 8192 & 32.30 & 34.01 & 3 & 37.19 \\
15,361 & 16,384 & 69.23 & 70.93 & 6 & 32.19 \\
22,529 & 23,552 & 101.53 & 103.24 & 4 & 37.80 \\
23,553 & 24,576 & 106.15 & 107.86 & 6 & 17.59 \\
24,577 & 25,600 & 110.76 & 112.47 & 6 & 16.61 \\
25,601 & 26,624 & 115.38 & 117.09 & 5 & 17.28 \\
32,769 & 33,792 & 147.69 & 149.39 & 6 & 29.92 \\
33,793 & 34,816 & 152.30 & 154.01 & 4 & 20.80 \\
35,841 & 36,864 & 161.53 & 163.24 & 3 & 30.85 \\
\hline
\end{tabular}

Table 4 RRT Peak frequencies for non-cutting (with air gap)

\begin{tabular}{lllcll}
\hline Sample start no & Sample stop no & $\begin{array}{l}\text { Workpiece } \\
\text { start }(\mathrm{mm})\end{array}$ & $\begin{array}{l}\text { Workpiece } \\
\text { stop }(\mathrm{mm})\end{array}$ & $\begin{array}{l}\text { Peak } \\
\text { frequency(hz) }\end{array}$ & Peak amplitude \\
\hline 1 & 1024 & 0 & 1.70 & 7 & 10.47 \\
1025 & 2048 & 4.61 & 6.32 & 6 & 18.01 \\
2049 & 3072 & 9.23 & 10.93 & 7 & 24.13 \\
8193 & 9216 & 36.92 & 38.62 & 7 & 26.34 \\
9217 & 10,240 & 41.53 & 43.24 & 9 & 30.56 \\
10,241 & 11,264 & 46.15 & 47.86 & 8 & 20.04 \\
17,409 & 18,432 & 78.46 & 80.16 & 6 & 15.20 \\
19,457 & 20,480 & 87.69 & 89.39 & 7 & 29.51 \\
20,481 & 21,504 & 92.30 & 94.01 & 7 & 15.45 \\
28,673 & 29,696 & 129.23 & 130.93 & 6 & 14.33 \\
37,889 & 38,912 & 170.76 & 172.47 & 7 & 20.59 \\
38,913 & 39,936 & 175.38 & 177.09 & 8 & 16.16 \\
\hline
\end{tabular}


Acknowledgements Science and Engineering Research Board (SERB), Department of Science and Technology (DST), Ministry of Science and Technology, Govt. of India fund this research work with sanction No. SB/FTP/ETA-0262/2013.

\section{Compliance with ethical standards}

Conflict of interest Authors confirm that there is 'No conflict of interest'.

Open Access This article is licensed under a Creative Commons Attribution 4.0 International License, which permits use, sharing, adaptation, distribution and reproduction in any medium or format, as long as you give appropriate credit to the original author(s) and the source, provide a link to the Creative Commons licence, and indicate if changes were made. The images or other third party material in this article are included in the article's Creative Commons licence, unless indicated otherwise in a credit line to the material. If material is not included in the article's Creative Commons licence and your intended use is not permitted by statutory regulation or exceeds the permitted use, you will need to obtain permission directly from the copyright holder. To view a copy of this licence, visit http://creativecommons .org/licenses/by/4.0/.

\section{References}

1. Altintas $Y$ (2012) Manufacturing automation: metal cutting mechanics machine tool vibrations and CNC design, 2nd edn. Cambridge University Press, Cambridge, pp 125-190. https:// doi.org/10.1017/CBO9780511843723.006

2. Quintana G, Ciurana J (2011) Chatter in machining processes: a review. Int J Mach Tools Manuf 51(5):363-376

3. Budak E (2006) Analytical models for high performance milling Part I cutting forces structural deformations and tolerance integrity. Int J Mach Tools Manuf 46(12-13):1478-1488

4. Toh CK (2004) Vibration analysis in high speed rough and finish milling hardened steel. J Sound Vib 278(1-2):101-115

5. Munoa J, Beudaert X, Dombovari Z, Altintas Y, Budak E, Brecher C, Stepan G (2016) Chatter suppression techniques in metal cutting. CIRP Ann 65(2):785-808

6. Wiercigroch M, Budak E (2001) Sources of nonlinearities chatter generation and suppression in metal cutting. Philosophical Transactions Royal Soc London Series Math Phys Eng Sci 359(1781):663-693

7. Zuperl U, Cus F, Kiker E, Milfelner M (2005) A combined system for off-line optimization and adaptive adjustment of the cutting parameters during a ball-end milling process. Strojniski Vestnik 51(9):542-559

8. Cus F, MilfelnerBalic MJ (2006) An intelligent system for monitoring and optimization of ball-end milling process. J Mater Process Technol 175(1-3):90-97
9. Prickett PW, Siddiqui RA, Grosvenor RI (2011) A microcontrollerbased end milling cutter monitoring and management system. The Int J Adv Manuf Technol 55(9-12):855-867

10. Jardine AK, Lin D, Banjevic D (2006) A review on machinery diagnostics and prognostics implementing condition-based maintenance. Mech syst signal process 20(7):1483-1510

11. Tong X, Liu Q, Pi S, Xiao Y (2019) Real-time machining data application and service based on IMT digital twin. J Intell Manuf 31:1-20

12. Bort CMG, Leonesio M, Bosetti P (2016) A model-based adaptive controller for chatter mitigation and productivity enhancement in CNC milling machines. Robotics Comput-Integr Manuf 40:34-43

13. Coppel R, Abellan-Nebot JV, Siller HR, Rodriguez CA, Guedea F (2016) Adaptive control optimization in micro-milling of hardened steels evaluation of optimization approaches. Int J Adv Manuf Technol 84(9-12):2219-2238

14. Marques JR, Machado IF, Cardoso JR, Barbosa PA (2014) The use of the Hilbert-Huang transform in the analysis of machining vibrations in machine tools. In: IECON 2014-40th annual conference of the IEEE industrial electronics society IEEE:3494-3500

15. Prasad BS, Prasad DS, Sandeep A, Veeraiah G (2013) Condition monitoring of CNC machining using adaptive control. Int J Autom Comput 10(3):202-209

16. Cheddadi Y, Cheddadi H, Cheddadi F, Errahimi F, Es sbai N (2020) Design and implementation of an intelligent low cost loT solution for energy monitoring of photovoltaic stations. SN Appl Sci 2:1165

17. Bellman RE (2015) Adaptive control processes: a guided tour. Princeton University Press, Princeton, NJ, pp 194-201

18. Landau ID, Lozano R, M'Saad M, Karimi A (2011) Adaptive control: algorithms, analysis and applications. Springer, New york

19. Huang NE, Shen SSP (2014) Hilbert-Huang transform and its applications, vol 16, 2nd edn. World Scientific Publishing Company, pp 1-16

20. Kalvoda T, Hwang YR (2010) A cutter tool monitoring in machining process using Hilbert-Huang transform. Int J Mach Tools Manuf 50(5):495-501

21. Susanto A, Liu CH, Yamada K, Hwang YR, Tanaka R, Sekiya K (2018) Milling process monitoring based on vibration analysis using hilbert-huang transform. Int J Automation Technol 12(5):688-698

22. Wei CC, Liu MK, Huang GH (2016) Chatter identification of face milling operation via time-frequency and Fourier analysis. Int J Automation Smart Technol 6(1):25-36

23. Mouli KVVNRC, Prasad BS, Sridhar AV, Alanka S (2020) A review on multi sensor data fusion technique in CNC machining of tailor-made nanocomposites. SN Appl Sci 2:1-12

Publisher's Note Springer Nature remains neutral with regard to jurisdictional claims in published maps and institutional affiliations. 